\title{
PRODUÇÃO PARA O AUTOCONSUMO E COMPRA DE ALIMENTOS NO SUL DA BAHIA: O CASO DO ASSENTAMENTO BOM JESUS
}

\author{
Valtemir Santos Nascimento ${ }^{1}$ \\ Vanderlei Franck Thies ${ }^{2}$
}

\begin{abstract}
RESUMO
A produção de alimentos para o próprio consumo integra de forma recorrente as estratégias de reprodução social das famílias agricultoras, o que contribui para a segurança alimentar e nutricional, a qualidade de vida e a ampliação da renda. $O$ avanço das formas de agricultura engendradas pelos impérios alimentares têm impulsionado a expansão da produção comercial especializada, tensionado a produção para o autoconsumo. O presente estudo tem por objetivo mensurar o valor da produção agropecuária para venda e autoconsumo e dos gastos com a compra de alimentos, procurando identificar sua contribuição e seu impacto na renda das famílias agricultoras. Através de estudo de caso, realizado junto a famílias assentadas no Baixo Sul da Bahia, evidenciou-se que a produção para o autoconsumo é prática recorrente e contribui de forma expressiva na renda das mesmas, estando baseada no cultivo diversificado de vegetais e com escassa presença de produção animal. Já a produção agropecuária de caráter comercial mostrou-se pouco diversificada e altamente dependente do cultivo de cacau. A compra de alimentos é bastante intensa e compromete parte considerável da renda das famílias, destacando-se a aquisição de itens de origem animal e ultraprocessados.
\end{abstract}

Palavras-chave: agricultores, alimentação, reforma agrária, renda.

\section{PRODUCTION FOR AUTOCONSUMPTION AND FOOD PURCHASE IN SOUTHERN BAHIA: THE CASE OF SETTLEMENT BOM JESUS}

\begin{abstract}
The production of food for own consumption repeatedly integrates the social reproduction strategies of farming families, which contributes to food security, quality of life and increased income. The advance of the forms of agriculture engendered by the food empires has driven the expansion of the specialized commercial production, tensioning the production for autoconsumption. The present study aims to measure the value of agricultural production for sale and autoconsumption and also the expenses with the purchase of food, seeking to identify their contribution and impact on the income of farming families. Through a case study, carried out with families settled in the South Bass of Bahia, it was shown that production for self-consumption is a recurrent practice and contributes significantly to the income of families, being

${ }^{1}$ Graduado em Agronomia (UFFS/Instituto Educar). E-mail: valtemir.snacimento@gmail.com

2 Graduado em Agronomia (UFPel). Mestrado e Doutorado em Desenvolvimento Rural (UFRGS). Professor do Instituto Federal Farroupilha (IFFAR - Alegrete). E-mail: vftc3@yahoo.com.br
\end{abstract}


based on the diversified cultivation of vegetables and with a little presence of animal production. The agricultural production of commercial character proved to be little diversified, being highly dependent on the cultivation of cocoa. The purchase of food is quite intense, compromising an expressive part of the families' income, highlighting the acquisition of items of animal origin and ultra-processed.

Keywords: farmers, food, land reform, income.

\section{INTRODUÇÃO}

O autoconsumo, ou "produção pro gasto", é compreendido como a parcela da produção agropecuária produzida pelas famílias camponesas que é destinada ao consumo da própria família, incluindo todos os produtos de origem animal e vegetal, na forma in natura ou processada (GRISA; SCHNEIDER, 2008a; FONTOURA, 2012).

Essa modalidade de produção contribui para a estabilidade econômica (LEITE, 2003), a formação da renda e a geração de melhores condições de vida no campo, favorece a reprodução social das unidades familiares de produção (GAZOLLA, 2004; GRISA, 2007; BUSATO et al., 2011; FONTOURA, 2012; JAEHN, 2019; THIES, 2020) e também faz frente à insegurança alimentar, além de apresentar maior sintonia cultural com as famílias (DOMBEK, 2006; DUVAL et al., 2012). Assim, a produção de alimentos para o autoconsumo fortalece as possibilidades de permanência dos agricultores no campo, gera menor dependência dos mercados e estende suas margens de manobra, o que lhes possibilita maior autonomia (PLOEG, 2008).

Por outro lado, o modelo de agricultura engendrado pelos impérios alimentares, baseado na especialização e no ganho de escala, na artificialização dos sistemas produtivos e no desenvolvimento de cadeias longas, implica a crescente desconexão entre produção e consumo, a desnaturalização das dietas e a elevação do poder dos supermercados (PLOEG, 2008; GAZOLLA; SCHNEIDER, 2017). Esses elementos, em conjunto, atuam como vetores contrários à produção para o autoconsumo. Essa modalidade de produção é típica das formas camponesa e familiar de agricultura, que apresentam diferentes graus de mercantilização, mas conservam a produção para autoconsumo como uma de suas estratégias de reprodução social.

Portanto, é parte do contexto das dinâmicas atuais de desenvolvimento rural a existência de forte tensionamento exercido pelas formas empresariais e capitalista de agricultura sobre a produção para o autoconsumo. Conforme Ploeg (2008), os impérios alimentares e os mercados agrícolas globais representam um novo fenômeno e geram fortes impactos na agricultura em qualquer lugar onde ela é desenvolvida. A lógica dos impérios alimentares busca mobilizar todos os espaços rurais e recursos disponíveis para a produção destinada ao mercado, desestimulando e limitando a produção alimentar diversificada para o autoconsumo. Esse tensionamento é acompanhado por um processo global de ampliação do protagonismo do capital financeiro, de intensificação do processamento dos alimentos e do poder da indústria alimentar, bem como da homogeneização da cultura alimentar (BURSCH; LOWRENCE, 2009; RITZER, 1983; NESTLE, 2013), que também atuam na contramão da produção para o autoconsumo.

A relevância da problemática analisada no presente artigo também advém de um cenário de mudanças e fragilização nas políticas públicas favoráveis à agricultura familiar e à reforma agrária, que haviam se iniciado em meados dos anos 1990 e que têm sofrido um processo de descontinuidade desde 2016 (MATTEI, 2017). Além disso, 
em termos empíricos, sua importância é atestada pelos dados do Censo Agropecuário 2017, que revelam que cerca de $40 \%$ dos estabelecimentos agropecuários, no Brasil, têm na produção para o autoconsumo sua principal finalidade (IBGE, 2017). Ainda, os dados da Pesquisa Nacional por Amostra de Domicílio Contínua (PNAD-C) revelam a elevação da proporção da população abaixo da linha da pobreza nos espaços rurais, que passou de 12,5\%, em 2014, para 17,5\%, em 2018 (PNAD-C, 2019).

Nesse contexto, de antagonismo global dos impérios alimentares à produção para o autoconsumo e a fragilização do apoio das políticas públicas, somados ao crescimento nacional da pobreza rural, emerge a relevância do estudo das relações entre a produção agrícola com caráter comercial e aquela destinada ao autoconsumo nas unidades familiares de produção agropecuária. Pretende-se contribuir para a compreensão das dinâmicas atuais de reprodução das famílias agricultoras, analisando suas práticas produtivas e de compra de alimentos.

Considerando esse cenário, o objetivo deste trabalho é mensurar tanto o valor da produção agropecuária destinada ao autoconsumo e a venda, como o valor dos gastos com a compra de alimentos oriundos de fora dos estabelecimentos das famílias agricultoras. Pretende-se dimensionar a contribuição da produção para autoconsumo e venda na composição da renda familiar e a proporção do rendimento familiar que é comprometido com a compra de alimentos.

Para tal, no ano de 2019 foi realizado estudo de caso junto às famílias do Projeto de Assentamento Bom Jesus (PABJ), no município baiano de Igrapiúna. Este assentamento é formado por dezenove família e possui cerca de quinze anos de história e, apesar de não ter ocorrido a demarcação definitiva dos lotes, as famílias têm desenvolvido ao longo desse tempo a produção comercial e para o autoconsumo. Além disso, observações preliminares de campo também mostraram a recorrência da compra de alimentos entre as famílias assentadas, o que torna o assentamento um espaço adequado para a análise proposta.

Com isso, o presente estudo busca contribuir para o entendimento das dinâmicas atuais de desenvolvimento rural, enfocando especificamente as práticas de produção e de compra de alimentos através de sua valoração econômica. Em termos teóricos ele está ancorado na Perspectiva Orientada aos Atores (LONG, 2007; LONG; PLOEG, 1994), a partir da qual utiliza especialmente as noções de estilos e formas de agricultura. Esses conceitos constituem-se como relevantes instrumentos heurísticos para a análise dos processos sociais e a interpretação das dinâmicas contemporâneas de desenvolvimento rural (PLOEG, 1994; SCHNEIDER; ESCHER, 2014).

A seção que segue discorre sobre as referências conceituais acionadas e, na sequência, descreve-se o método utilizado para a realização do estudo. Depois disso, o contexto pesquisado é apresentado, sendo seguido e complementado pela exposição e discussão dos resultados observados. Com base neles, encerrando o artigo, apresenta-se as considerações finais.

\section{ABORDAGEM CONCEITUAL: OS ESTILOS E AS FORMAS DE AGRICULTURA}

A modernização da agricultura é compreendida como uma grande transformação nas suas dinâmicas sociais e produtivas, mediante o uso intensivo de máquinas, insumos industrializados e sementes melhoradas, ocorrendo um processo de crescente externalização do processo produtivo (CONTERATO, 2004; ALMEIDA, 2011). Isso implicou na ampliação da sua mercantilização, gerando fortes mudanças nos sistemas produtivos, cuja produção para o autoconsumo passa a rivalizar e disputar espaço e recursos com a produção comercial (GAZOLLA, 2004; GRISA, 2007). 
A mercantilização da agricultura é entendida, conforme Conterato et al (2011), como um processo social no qual o mercado se apresenta como a esfera primordial e organizadora da reprodução social dos agricultores. Ploeg (2008) aponta que, através do jogo de forças no mercado, se estabelece e se controla globalmente os preços de produção e das mercadorias, com crescente imposição dos interesses dos impérios alimentares sobre o conjunto da agricultura onde quer que ela seja desenvolvida.

Nesse contexto adverso, os agricultores, no exercício de sua capacidade de agência, são ativos processadores de informações e produtores de estratégias, mobilizando seus recursos em distintas condições sociais, econômicas e ecológicas (LONG, 2007). De acordo com a disponibilidade de recursos e com seus repertórios culturais eles configuram diferentes estilos de agricultura e, através desses, modulam sua inserção na sociedade englobante (WANDERLEY, 2003), de forma mais ou menos mercantilizada (SCHNEIDER, 2010).

Assim, os estilos de agricultura representam os distintos modos de fazer agricultura, constituídos a partir das necessidades e possibilidades dos agricultores organizarem suas relações sociais e produtivas e, também, a partir de diferentes lógicas cognitivas que são inerentes à heterogeneidade social dos espaços rurais (CONTERATO et al., 2011). Portanto, segundo as diferentes estratégias e com base nas distintas formas pelas quais os agricultores se relacionam com a sociedade englobante é que se configuram variados estilos de agricultura e, dentro de cada um deles, as modalidades de produção comercial e de autoconsumo podem ganhar maior ou menor relevo, bem como a prática de compra de alimentos externos ao estabelecimento rural pode ser mais ou menos intensamente ativada. Cabe destacar, conforme Garcia Jr. e Heredia (2009), a alternatividade existente na produção agrícola, que pode ser diferida no tempo, sendo destinada para o autoconsumo ou para a venda de acordo com as circunstâncias e segundo as estratégias de reprodução social desenvolvidas pelos agricultores.

A configuração de distintos estilos de agricultura representa a diversidade de interesses e estratégias dos agricultores frente às imposições de um contexto sob crescente influência dos impérios alimentares (PLOEG, 2008). Os estilos de agricultura, como fluxo de atividades conscientemente organizadas ao longo do tempo (PLOEG, 1994), são constituídos na dinâmica nem sempre convergente das aspirações dos agricultores com os interesses de outros atores. Daí emergem três diferentes formas de agricultura que, de acordo com Ploeg (2008), são a camponesa, a empresarial e a capitalista.

A forma camponesa se define como um modelo agrícola que se fundamenta no uso sustentado do capital ecológico, orientado para a melhoria das condições de vida das famílias. Esse tipo de agricultura se caracteriza por sua multifuncionalidade, mão de obra basicamente familiar, produção voltada para reprodução da unidade de produção e também para o mercado. A produção camponesa se caracteriza pelo seu reduzido grau de mercantilização, tendo um modelo de relação com os mercados fortemente baseado em circuitos curtos e descentralizados, onde produção e consumo alimentar possuem vínculos mais locais e regionais. Nessa forma de agricultura ocorre a pequena produção mercantil, que tende a escapar do controle direto do capital, tendo como uma de suas características a luta por autonomia (PLOEG, 2008, 2016).

A forma empresarial de agricultura é altamente especializada e voltada ao mercado. É fortemente dependente de capital financeiro e de tecnologias e insumos industriais, apresentando elevado grau de mercantilização. Exceto o trabalho, todos os demais elementos entram no processo produtivo como mercadorias, ocorrendo a produção simples de mercadorias. Já a forma capitalista de agricultura é guiada pela 
maximização do lucro e emerge sob a égide do modelo agroexportador, constituída por uma extensa rede de empresas agrícolas de alta mobilidade que utilizam força de trabalho assalariada. Nessa forma de agricultura ocorre a produção capitalista de mercadorias, com a completa mercantilização do processo de produção. As formas de agricultura empresarial e capitalista operam crescentemente em escala global, sob controle do capital, através de um modelo centralizado que busca subordinar, conforme seus interesses, a produção e o consumo mundial de alimentos (PLOEG, 2008, 2009).

Cabe destacar que essas formas de agricultura são instrumentos heurísticos e não se apresentam na realidade de forma pura ou isolada, podendo ocorrer sobreposições no universo empírico. Assim, considerando esses elementos, em síntese, sustenta-se que na forma camponesa de agricultura estão presentes mais intensamente os estilos de agricultura mais autônomos e menos mercantilizados, nos quais o autoconsumo ganha maior relevo, reduzindo a intensidade da compra externa de alimentos pelas famílias agricultoras. Nas formas empresariais e, especialmente na capitalista, a produção para o autoconsumo é crescentemente subsumida pela produção comercial.

\section{MÉTODO}

A pesquisa foi realizada através de estudo de caso, dado que a questão de estudo diz respeito a um fenômeno contemporâneo, inserido em um contexto delimitado e com um grupo social específico, onde se busca entender em profundidade determinados aspectos da dinâmica social (YIN, 2001). Conforme Silveira e Córdova (2009), em relação aos objetivos, a pesquisa é descritiva e quanto aos procedimentos é classificada como de campo, mesclando o caráter qualitativo e quantitativo, pois aprofunda a compreensão do comportamento social dos assentados em relação à destinação da produção agrícola e a compra de alimentos, valendo-se, para tal, da mensuração e análise de variáveis quantitativas, oriundas dos sistemas produtivos e associadas aos hábitos alimentares das famílias.

Além de revisão de literatura e consulta a fontes secundárias, realizou-se pesquisa de campo. Foram coletados dados primários, durante o mês de fevereiro de 2019, por meio de entrevistas, utilizando-se um roteiro semiestruturado e a observação participante. A pesquisa de campo foi realizada no PABJ, no município baiano de Igrapiúna e as memórias de um dos autores também serviram como fonte complementar de informações, visto que o mesmo é morador do referido assentamento.

A proposta da pesquisa foi inicialmente apresentada para todas as famílias em assembleia do assentamento e elas puderam optar por participar ou não do estudo, sendo esse o critério de seleção dos participantes. As entrevistas foram agendadas de acordo com a disponibilidade das onze famílias que optaram por participar da pesquisa, o que representou $58 \%$ das famílias do assentamento. A maioria das entrevistas ocorreu nos finais de semana e à noite, o que favoreceu a participação de um maior número de integrantes das famílias. Elas foram gravadas e também realizou-se anotações em diário de campo.

Os dados relacionados aos sistemas produtivos, produção para o autoconsumo e renda familiar foram gerados e processados conforme os procedimentos descritos por Lima et al. (1995). Em relação ao consumo de alimentos das famílias, foram anotados os itens e quantidades de produtos comprados e consumidos semanal, mensal ou anualmente, conforme os hábitos das famílias. Esses dados foram autodeclarados e correspondem ao ano de 2018. Para o cálculo do valor gasto com a compra desses alimentos foram tomados, em fevereiro de 2019 , 
os preços desses itens nos estabelecimentos comerciais frequentados de forma mais recorrente pelos assentados e calculou-se o preço médio de cada produto. $\mathrm{O}$ gasto com a compra de alimentos resultou da multiplicação do preço médio de cada item pela quantidade adquirida ao longo de um ano. A soma dos valores anuais gastos na compra de todos os itens alimentares resultou no gasto total de cada família com a compra de alimentos.

O cálculo do valor da produção de autoconsumo também considerou os preços médios pagos pelos produtos nos mercados locais. Isso minimizou a subvalorização dessa produção, quando o preço dos produtos é atribuído segundo a percepção de preço dos agricultores, como destaca o trabalho de Tonezer et al. (2019).

\section{RESULTADOS E DISCUSSÃO}

\subsection{CARACTERIZAÇÃO DO ASSENTAMENTO BOM JESUS}

O PABJ está localizado a $30 \mathrm{~km}$ da sede do município de Igrapiúna. O município está localizado na região da Costa do Dendê e faz parte do território Baixo Sul, que é formado por quinze municípios situados na zona litorânea da Bahia. No município predomina a agricultura familiar, que representa $79,42 \%$ dos estabelecimentos rurais. As culturas permanentes ocupam a maior parte da área agrícola cultivada do município, destacando-se, sobretudo, o cacau, presente em $75,99 \%$ dos estabelecimentos e em proporções bem menores o guaraná, a seringueira, o cravo da índia, o dendê e a banana. As culturas temporárias estão presentes em pequeno número de estabelecimentos e a produção pecuária é diminuta no conjunto do município (IBGE, 2017).

A criação do PABJ se insere no contexto histórico de lutas camponesas por terra na região sul da Bahia, que envolve a participação de comunidades quilombolas, movimento sindical, Comissão Pastoral da Terra e do Movimento dos Trabalhadores Rurais Sem Terra (MST). As famílias deste assentamento são oriundas de Igrapiúna e municípios do entorno, tendo tomado parte da luta por terra junto ao MST no ano de 2003, quando constituíram o acampamento Camucinho, em Igrapiúna. A ocupação da área da fazenda Manjerona, que possuía 400 ha, ocorreu em janeiro de 2004 e sua desapropriação ocorreu no ano de 2006. Nesse período as famílias viabilizaram sua permanência na área em acordo estabelecido com o proprietário, pois este tinha interesse em agilizar a desapropriação da fazenda.

Atualmente dezenove famílias fazem parte do assentamento. Quarenta pessoas constituem as onze famílias que participaram da pesquisa, destacando-se a elevada presença de crianças e jovens com até dezoito anos, que constituem cerca de dois terços dos integrantes das famílias. A comunidade dispõe de uma escola pública municipal multisseriada, com aulas até o quinto ano do ensino fundamental. Depois disso os estudantes são transferidos para outra escola, no assentamento vizinho, onde estudam até o nono ano. Após concluir essas fases, usualmente os adolescentes se encaminham para a cidade, para cursar o ensino médio. O nível de escolaridade predominante no conjunto dos entrevistados está na faixa da quinta até oitava série.

As famílias têm acesso à água encanada em suas residências e desde 2010 passaram a dispor de energia elétrica no assentamento. O serviço de internet não estava disponível no assentamento e o de telefonia celular mostrava-se bastante limitado, apresentando cobertura apenas em alguns pontos específicos do assentamento. Os meios de transporte do assentamento para a cidade são vans, ônibus escolar e caminhões, que prestam serviços de transporte. Geralmente, nos 
finais de semana os assentados se deslocam para a cidade, onde realizam as compras dos alimentos que não são produzidos em seus lotes e que são comprados nos mercados locais.

As famílias do assentamento possuem pouco capital imobilizado em máquinas, equipamentos e benfeitorias destinadas às atividades agropecuárias. Além disso, a produção comercial é fortemente canalizada para empresas, com intermediação de atravessadores. O assentamento possui uma casa de farinha operada manualmente, sendo essa a única unidade de processamento de alimentos existentes no local. Os lotes das famílias possuem tamanho médio de seis hectares.

$\mathrm{Na}$ área do assentamento, antes de sua constituição, predominava a monocultura de cacau e este segue tendo grande peso nos atuais sistemas produtivos. As famílias assentadas seguem cultivando cacau com finalidade comercial. O sistema de cultivo do cacau no assentamento é o tradicional, denominado cacau-cabruca, cuja produção é feita de forma integrada à floresta, configurando um sistema agrossilvicultural, com elevada contribuição para a conservação ambiental. Nesse sistema não se retira a mata nativa para implantar um monocultivo de cacau, mas se faz o raleamento de árvores de menor porte, mantendose as maiores (PIASENTIN, 2011; LOBÃO, 2013). Outras espécies vegetais, especialmente frutíferas, podem integrar esse sistema, como: bananeira, abacate, laranja, jaca, cajá e rabotam.

Além disso, em pequena escala, as famílias mantêm outros cultivos, especialmente mandioca, graviola, cupuaçu, mamão e hortaliças. Estes são destinados prioritariamente para o consumo familiar, mas também podem ser comercializados pelas famílias, em feiras livres, no município de Igrapiúna e cidades mais próximas. É importante salientar que o conjunto das atividades agropecuárias no assentamento seguem os princípios da agroecologia, estando em curso o processo de certificação da produção.

O diálogo com as famílias assentadas tornou evidente a fragilidade do acesso às políticas públicas. Além dos lotes não terem sido oficialmente demarcados pelo Instituto Nacional de Colonização e Reforma Agrária (INCRA), apesar de transcorridos quinze anos de constituição do assentamento, as famílias não contavam com serviço público de Assistência Técnica e Extensão Rural e também não eram beneficiadas por fontes públicas de crédito agrícola. $O$ acesso aos mercados institucionais mostrou-se bastante limitado, alcançando apenas cinco famílias em 2014, através do Programa Nacional de Alimentação Escolar (PNAE).

\subsection{A PRODUÇÃO AGROPECUÁRIA NO ASSENTAMENTO}

Todas as famílias pesquisadas produzem alimentos para o autoconsumo, que representa $12,83 \%$ do PB (Produto Bruto) ${ }^{3}$ total. Cada uma delas produz entre dez e quinze tipos de alimentos para o consumo familiar e, ao todo, produzem 21 diferentes produtos para o autoconsumo. Observa-se aí uma considerável diversidade de produtos que são destinados para o consumo próprio, com destaque para as frutas (laranja, jaca, graviola, abacate, rabotam, acerola, abacaxi, cajá) e hortaliças (jiló, quiabo, maxixe, abóbora, salsa, coentro, cebolinha, pepino e hortelã). Assim, no caso estudado, a produção para o autoconsumo contribui para a configuração de estilos de agricultura diversificados e com base em princípios agroecológicos, em consonância com resultados do estudo de Duval et al. (2012).

\footnotetext{
${ }^{3}$ O Produto Bruto representa o valor monetário de tudo o que é produzido pela família, considerando tanto os diretamente consumidos como aqueles que são comercializados. O PB resulta do somatório da multiplicação da quantidade produzida pelo preço correspondente de cada produto.
} 
Os dados evidenciam que a produção para o autoconsumo mantém-se como uma estratégia contemporânea levada a cabo por estes agricultores. Não se trata de resquícios do passado, mas uma prática social e produtiva amplamente acionada pelas famílias assentadas na perspectiva de sua reprodução social, o que corrobora os resultados de outros trabalhos de pesquisa (GRISA, 2007; DUVAL, 2009; DOMBECK, 2012; JAEHN, 2019; THIES, 2020) e revela a face camponesa das formas de agricultura desenvolvidas por estas famílias.

Além destes produtos, destinados exclusivamente para o autoconsumo, outros quatro são produzidos prioritariamente para o autoconsumo mas parcelas deles também são destinados para a venda, sendo eles: couve, cupuaçu, farinha de mandioca e banana. Eles são bastante secundários em termos do PB total e na composição da renda familiar, evidenciando sensível dissociação entre a produção destinada à venda e aquela destina ao autoconsumo. Diferente de outros trabalhos de pesquisa, que apontam elevada conexão e complementaridade entre a produção para o autoconsumo e para a venda (GAZOLA, 2004; SALAMI, 2009; BUSATO et al., 2011), no caso estudado, observa-se forte desconexão entre a produção comercial e aquela destinada ao autoconsumo, sendo a alternatividade (GARCIA JR.; HEREIDA, 2009) uma estratégia pouco acionada e com reduzido impacto no valor da produção.

Todas as famílias desenvolvem produção agrícola para a venda, que representa $87,17 \%$ do PB total, constituída especialmente por cacau $(68,87 \%)$ e guaraná $(14,25 \%)$. Ou seja, na configuração de seus estilos de agricultura, essas famílias apresentam elevada dependência desses produtos na composição de suas estratégias de comercialização, ampliando sua vulnerabilidade relativamente às famílias com maior diversificação produtiva. Somam-se a eles, em proporções bem menores, na composição do PB total: seringueira, banana, farinha de mandioca, abacaxi, inhame, mandioca, urucum, cupuaçu e couve.

O cacau é produzido por todas as famílias, o guaraná por $90 \%$ delas e a seringueira e banana são cultivadas por cerca de metade das famílias. Esses são os principais cultivos que compõem a maior parte do PB da comercialização, dado que a produção animal é incipiente no assentamento, pois apenas duas famílias desenvolvem tal atividade. Elas criam galinhas que suprem cerca de metade da sua demanda anual. Conforme as observações de campo, a ampliação da produção animal é limitada, sobretudo, pela reduzida área de terra disponível para cada família (cerca de cinco ha), sendo que a maior parte dessas áreas estão ocupadas pelos cultivos comerciais, o que geraria, para aumento da produção animal, elevação dos custos com a aquisição de alimentos para os mesmos. Portanto, não há produção animal para venda e sua produção para o autoconsumo é pouco expressiva. Isso tende a reduzir a magnitude do valor total da produção para o autoconsumo. Pois, a presença de produtos de origem animal tende a exercer influência na elevação do PB de autoconsumo de famílias assentadas, sendo mais expressivo em sistemas produtivos com estilos de agricultura mais especializados na produção animal, como demonstrado por Fontoura (2012) e Jahen (2019).

$O$ valor médio familiar do PB de autoconsumo anual é de $R \$ 1.474,86$, todavia a faixa de variação é bastante grande (mínimo de $R \$ 290,00$ e máximo de $R \$$ $2.439,00)$, com predomínio de valores em torno de $R \$ 1.200,00$. Para a grande maioria das famílias, a contribuição relativa da produção de autoconsumo no PB total fica entre $10 \%$ e $20 \%$, como se observa na Figura 1 . Ao agregar-se os diferentes itens alimentares que o compõem, a produção para o autoconsumo (como visto, representa $12,83 \%$ do PB total) torna-se a segunda atividade mais importante na composição do PB total, levemente superior à contribuição da venda de guaraná (que representa $12,43 \%$ do PB total). 
Figura 1 - Participação relativa da produção para o autoconsumo e venda no PB total de cada família do PABJ, em 2018.

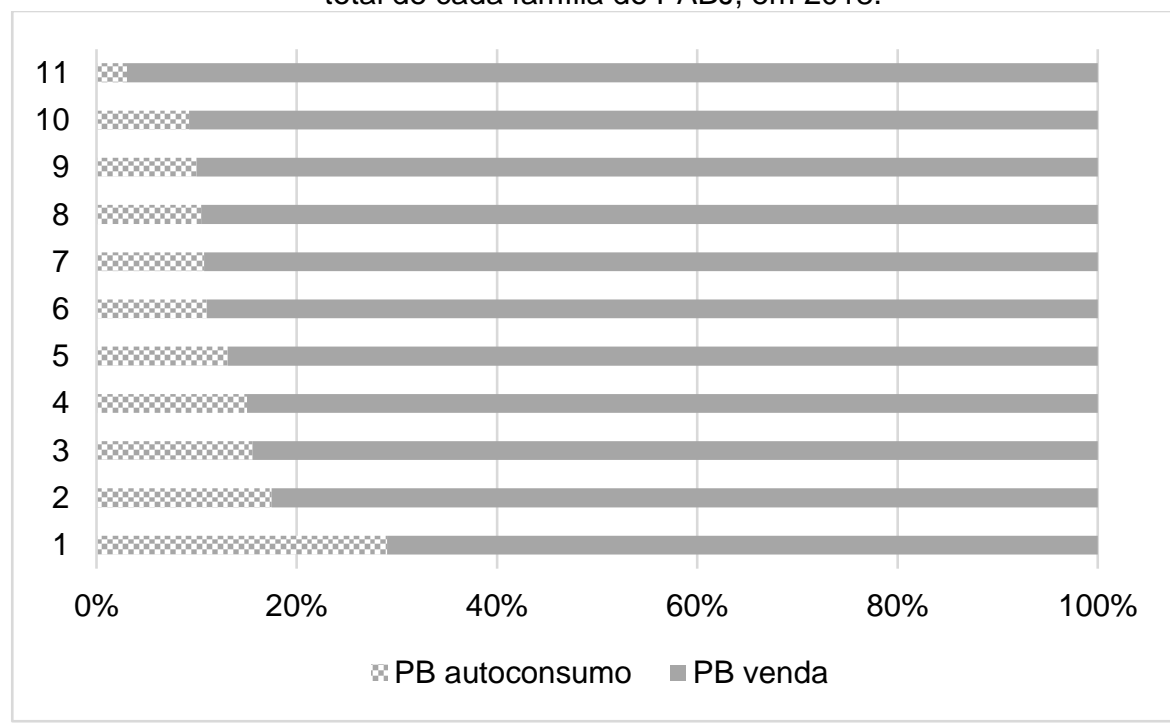

Fonte: Dados da pesquisa de campo, 2019.

Em sua análise da produção para o autoconsumo entre agricultores familiares de diferentes regiões do RS, Grisa (2007) aponta que a contribuição média da produção de autoconsumo na composição do PB total variava de $25,50 \%$ a $31,80 \%$. No caso das famílias estudadas esse valor é inferior (12,83\%), mas se mostra dentro da faixa de valores encontrados por Jahen (2019), que analisou diferentes sistemas produtivos de assentamentos e encontrou diferentes tipos, cujo PB do autoconsumo variava entre $0,4 \%$ e $16,4 \%$ do PB total.

Cabe destacar, como demonstra Leite (2003), a variabilidade relativa da contribuição da produção para autoconsumo na composição da renda total das famílias em diferentes assentamentos, todavia em todos os casos a produção para autoconsumo desempenha papel fundamental no balanço orçamentário. Além disso, destaca o mesmo autor, ela apresenta importante efeito anticíclico, pois pode compensar as fases de menor rendimento monetário do lote, contribuindo para equilibrar a relação entre a oferta monetária irregular ao longo do ano gerada pela temporalidade descontínua do ciclo agrícola (GARCIA JR.; HEREIDA, 2009) com a demanda regular por alimentos.

Diversos estudos têm apontado a importância do trabalho feminino na produção para o autoconsumo e a diferenciação de gênero nas atividades rurais (GRISA; SCHNEIDER, 2008b; MENASCHE et al., 2008; DUVAL, 2009; OLIVEIRA et al., 2015). No caso estudado isso também foi percebido, em conformidade com o apontado por Garcia Jr. e Hereida (2009), que destacam o processo de diferenciação de gênero associado a divisão de espaços e papéis dos indivíduos no que tange a produção e consumo entre os camponesas, configurando o mundo das mulheres e dos homens como domínios distintos e complementares. Durante as entrevistas as declarações masculinas apontavam o envolvimento de toda família na produção para o autoconsumo, sem distinção de gênero. Todavia, as declarações femininas e a 
observação participante permitiram perceber o maior protagonismo das mulheres na produção para o autoconsumo. Na produção comercial, destacadamente de cacau e guaraná, percebe-se presença mais intensa do trabalho masculino nas atividades de poda e roçada, mas nas atividades de colheita e pré-beneficiamento há intensa participação feminina.

\subsection{COMPOSIÇÃO DA RENDA FAMILIAR}

O valor médio da renda familiar total é de $R \$ 1.241,47$ por mês, com o predomínio de valores na faixa de $R \$ 1.100,00$ a $R \$ 1.800,00$. São quatro famílias que possuem renda total inferior a um salário mínimo mensal. Em termos per capita a situação é mais delicada, pois apenas uma família supera o valor de um salário mínimo mensal. Em termos médios, para o conjunto das famílias, a renda per capita mensal é de $R \$ 310,37$, predominando valores na faixa de $R \$ 200,00$ a $R \$ 400,00$.

Considerando os parâmetros brasileiros para a definição de pobreza e extrema pobreza ${ }^{4}$, nenhuma família seria enquadrada nessa situação, dado que aquela com menor renda per capita mensal alcança o valor de $R \$ 183,84$. Todavia, ao se considerar o parâmetro de extrema pobreza da Organização das Nações Unidas (ONU), para o monitoramento dos Objetivos de Desenvolvimento Sustentável (ODS) ${ }^{5}$, têm-se que três famílias estariam abaixo da linha da extrema pobreza e uma delas não é beneficiária do Programa Bolsa Família (PBF).

O baixo rendimento mensal per capita é explicado, em parte, pelo perfil etário das famílias, dada a existência de muitas crianças que não desempenham atividades produtivas. Isso afeta diretamente o equilíbrio entre a capacidade produtiva e a necessidade de consumo das famílias, em que a solidariedade intradoméstica explica, no caso estudado, a manutenção dos mais jovens pelos mais velhos, em função do ciclo de vida do grupo doméstico (GARCIA JR.; HEREIDA, 2009). Isso fica evidente ao se analisar os núcleos familiares que alcançam os maiores valores de renda per capita mensal, pois todos eles são compostos por apenas um indivíduo adulto. Com esse perfil existem três famílias que auferem renda média per capita mensal de $R \$ 871,54$, mostrando-se bastante superior à média do conjunto das famílias. Essas três famílias não recebem nenhum benefício previdenciário e sua renda é exclusivamente oriunda de atividades agrícolas.

Como se observa na Figura 2, a renda agrícola está presente em todas as famílias e na grande maioria dos casos é a principal fonte de renda. Destaca-se também que pouco mais da metade das famílias são beneficiárias do PBF e, em todos esses casos, a renda agrícola é maior que o referido benefício, demonstrando o caráter complementar que o programa desempenha na composição da renda total dessas famílias. Destaca-se que cerca de um terço das famílias tem como única fonte de renda a atividade agropecuária.

\footnotetext{
${ }^{4}$ O Decreto $n^{\circ}$ 8.974, de 29 de junho de 2016, define que uma família está em situação de pobreza quando a renda per capita mensal for de até $R \$ 170,00$ e extrema pobreza quando a renda per capita mensal for de até $\mathrm{R} \$ 75,00$.

${ }^{5}$ Nesse caso considera-se o valor diário per capita de U\$1,90 dólares.
} 
Figura 2 - Contribuição relativa das diferentes modalidades de renda na renda total das famílias do PABJ, em 2018.

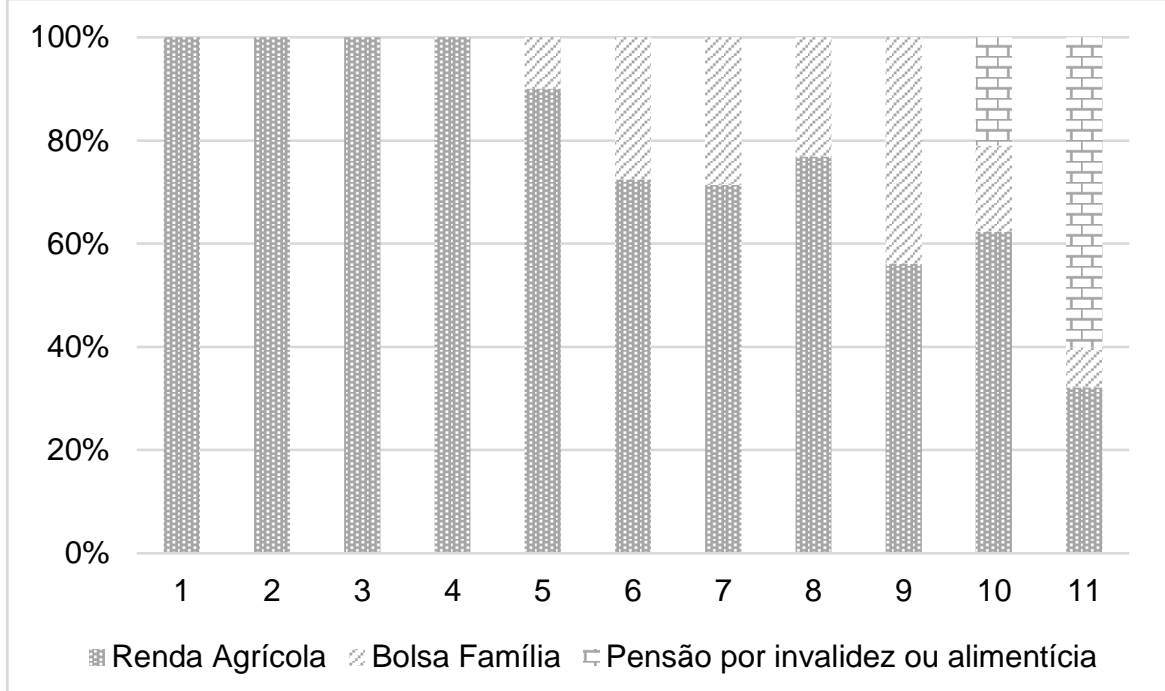

Fonte: Dados da pesquisa de campo, 2019.

A composição relativa da renda total do conjunto das famílias é assim constituída: renda agrícola $(74,6 \%)$; renda do PBF $(15,9 \%)$; pensão por invalidez e alimentícia $(9,5 \%)$. Ou seja, em termos da composição de suas rendas, são famílias fortemente agrícolas. A predominância da renda agrícola reforça a importância da produção para o autoconsumo, pois como apontam Pozzebom et al. (2015), essa é uma prática bastante vantajosa para as famílias porque, em termos econômicos, permite que invistam em outras necessidades os recursos financeiros economizados com a produção daqueles alimentos consumidos pelas próprias famílias.

Cabe destacar que não existem aposentados entre as famílias pesquisadas. Isso revela um perfil demográfico distinto do panorama nacional apontado por Maia (2014), que destaca o envelhecimento da população rural e a presença crescente de aposentados nos domicílios rurais, conforme os dados dos últimos três Censos Demográficos. Tampouco se observaram casos de famílias que desenvolviam atividades não agrícolas, ou atividades agrícolas fora do estabelecimento, para a obtenção de renda. Portanto, nos casos estudados, a pluriatividade não é uma estratégia acionada pelas famílias, reforçando um caráter mais agrícola, pois, por um lado, priorizam a alocação do trabalho familiar no desenvolvimento do próprio estabelecimento. Por outro lado, isso também se explica pelo limitado dinamismo da economia regional, que fragiliza os nexos intersetoriais e a oferta de ocupações não agrícolas para as famílias agricultoras, conforme apontado por Conterato (2008).

\subsection{COMPRA DE ALIMENTOS E IMPACTO NA RENDA DAS FAMÍLIAS}

A pesquisa mostrou que as famílias assentadas consomem mais de 40 itens alimentares e, em torno da metade deles é oriunda dos sistemas produtivos das próprias famílias, com destaque para as frutas e hortaliças. Os demais produtos, como cereais e produtos de origem animal são adquiridos através de compras locais, 
sobretudo, em supermercados e feiras na cidade de Igrapiúna e Camamu. A Tabela 1 apresenta os principais itens adquiridos, o volume consumido e o valor total desembolsado pelo conjunto das famílias ao longo de um ano. Destaca-se que os três itens que mais oneram as famílias são as carnes (bovina, de peixe e de frango), que juntas representam $56,74 \%$ de seu gasto total. Se a eles forem somados os demais gastos com produtos pecuários (carne suína, ovos, leite em pó, mortadela e calabresa), o valor total gasto com a compra de derivados animais alcança $70,29 \%$ dos gastos alimentares.

Tabela 1 - Principais itens alimentares comprados pelas famílias do PABJ, em 2018.

\begin{tabular}{lccrrr}
\hline Produto & Quantidade & \multicolumn{2}{c}{ Valor unitário } & \multicolumn{2}{c}{ Valor total } \\
\hline Carne bovina $(\mathrm{kg})$ & 696 & $\mathrm{R} \$$ & 17,00 & $\mathrm{R} \$$ & $11.832,00$ \\
Peixes $(\mathrm{kg})$ & 840 & $\mathrm{R} \$$ & 12,00 & $\mathrm{R} \$$ & $10.080,00$ \\
Carne de frango $(\mathrm{kg})$ & 954 & $\mathrm{R} \$$ & 4,50 & $\mathrm{R} \$$ & $4.293,00$ \\
Leite em pó $(\mathrm{kg})$ & 198 & $\mathrm{R} \$$ & 17,00 & $\mathrm{R} \$$ & $3.366,00$ \\
Feijão $(\mathrm{kg})$ & 704 & $\mathrm{R} \$$ & 4,00 & $\mathrm{R} \$$ & $2.816,00$ \\
Arroz $(\mathrm{kg})$ & 888 & $\mathrm{R} \$$ & 2,70 & $\mathrm{R} \$$ & $2.397,60$ \\
Biscoito $(\mathrm{kg})$ & 696 & $\mathrm{R} \$$ & 3,20 & $\mathrm{R} \$$ & $2.227,20$ \\
Café $(\mathrm{kg})$ & 144 & $\mathrm{R} \$$ & 10,00 & $\mathrm{R} \$$ & $1.440,00$ \\
Ovos $(\mathrm{dúzia})$ & 432 & $\mathrm{R} \$$ & 3,00 & $\mathrm{R} \$$ & $1.296,00$ \\
Açúcar $(\mathrm{kg})$ & 634 & $\mathrm{R} \$$ & 2,00 & $\mathrm{R} \$$ & $1.268,00$ \\
Alho $(\mathrm{kg})$ & 84 & $\mathrm{R} \$$ & 14,50 & $\mathrm{R} \$$ & $1.218,00$ \\
Cebola $(\mathrm{kg})$ & 336 & $\mathrm{R} \$$ & 3,00 & $\mathrm{R} \$$ & $1.008,00$ \\
Óleo de soja $(\mathrm{l})$ & 240 & $\mathrm{R} \$$ & 3,50 & $\mathrm{R} \$$ & 840,00 \\
Mortadela $(\mathrm{kg})$ & 144 & $\mathrm{R} \$$ & 5,00 & $\mathrm{R} \$$ & 720,00 \\
Carne suína $(\mathrm{kg})$ & 59 & $\mathrm{R} \$$ & 10,00 & $\mathrm{R} \$$ & 590,00 \\
Farinha de milho $(\mathrm{kg})$ & 132 & $\mathrm{R} \$$ & 3,80 & $\mathrm{R} \$$ & 501,60 \\
Calabresa $(\mathrm{kg})$ & 36 & $\mathrm{R} \$$ & 8,00 & $\mathrm{R} \$$ & 288,00 \\
\hline Total & - & & - & $\mathrm{R} \$$ & $\mathbf{4 6 . 1 8 1 , 4 0}$ \\
\hline
\end{tabular}

Fonte: Dados da pesquisa de campo, 2019.

Os elevados gastos com a compra de produtos pecuários coloca em questão a composição dos sistemas produtivos e dos estilos de agricultura baseados exclusivamente na produção vegetal. No caso estudado, conformado por famílias que incluem em suas dietas produtos pecuários, mas não desenvolvem sua produção, essa configuração evidencia um forte limite, pois os gastos com a aquisição de derivados animais representam cerca de dois terços dos gastos com a compra de alimentos. Esse esforço financeiro, representado pelos gastos com a compra de carne, remete ao simbolismo de seu consumo. Além da importância nutricional, a carne tem elevado valor simbólico nas comunidades camponesas e seu consumo constitui uma prática social que amplia o status dos comensais, representando um alimento forte (WEDIG; MENASCHE, 2008; SALAMI, 2009), o que justifica o elevado dispêndio monetário para garantir seu consumo. 
Observando-se a composição das dietas das famílias estudadas, que incluem a presença de produtos processados e ultraprocessados (mortadela, leite em pó e biscoitos), aponta-se que esses itens poderiam ser substituídos por alimentos que já são produzidos pelas famílias (como ovos de galinha), ou que poderiam passar a ser produzidos (como leite, carnes e biscoitos caseiros). Isso qualificaria suas dietas e geraria impacto positivo na renda familiar, já que os itens mencionados representam $13,67 \%$ dos gastos com a compra de alimentos, que não mais precisariam ser adquiridos.

Ao que se pode observar no trabalho de campo, a substituição dos produtos industrializados e ultraprocessados por alimentos de origem animal produzidos pelas próprias famílias esbarra em dois limites: a) por um lado, em termos objetivos, como destacado anteriormente, ela é limitada pelo reduzido espaço agrícola disponível, dado que as famílias dispõem área equivalente a cerca de um quarto do módulo fiscal do município de Igrapiúna, que é de vinte ha; b) por outro lado, em termos mais simbólicos, a tendência de crescente industrialização dos alimentos (PLOEG, 2008) e as estratégias impulsionadas pelas industrias alimentares, entre eles o lobby e a propaganda (NESTLE, 2013), bem como a homogeneização e padronização cultural e das dietas alimentares (RITZER, 1983), além do alegado baixo custo, a disponibilidade e facilidade de armazenamento, parece estar conseguido afetar as preferências alimentares das famílias assentadas.

$\mathrm{Na}$ Figura 3 observa-se os valores da renda total e do gasto total com a compra de alimentos das famílias assentadas. O valor médio gasto com a compra de alimentos é de $R \$ 5.195,24$ por ano, variando de $R \$ 2.191,20$ até $R \$ 8.672 .10$.

Figura 3 - Renda total e gastos com a compra de alimentos das famílias do PABJ, em 2018.

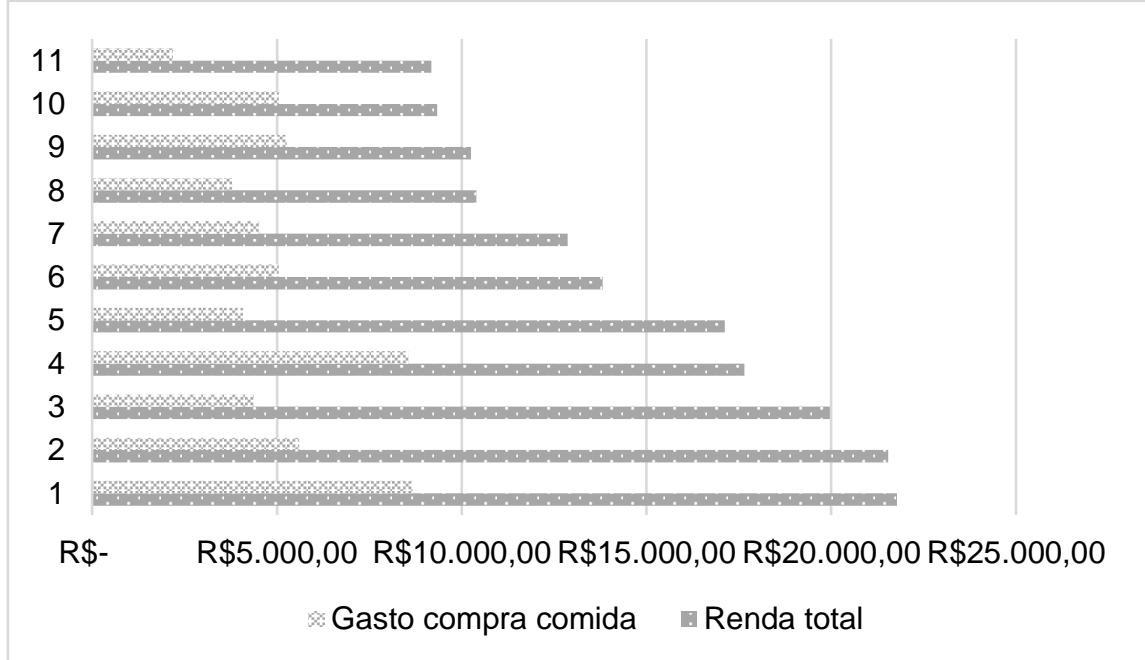

Fonte: Dados da pesquisa de campo, 2019.

O conjunto dos gastos com a compra de alimentos absorve $34,87 \%$ da renda total das famílias pesquisadas. Em termos relativos, esses gastos comprometem de $21,83 \%$ a $54,18 \%$ da renda dessas famílias. Ou seja, em que pese a existência de produção para o autoconsumo em todas as famílias, elas gastam, em média, cerca de um terço do rendimento total com a compra de alimentos, evidenciando o 
expressivo peso deste dispêndio no rendimento familiar. Como demonstrado, boa parte das famílias possuem baixos níveis de rendimento, o que remete à importância estratégica delas repensarem suas práticas de produção e consumo alimentar.

\section{CONSIDERAÇÕES FINAIS}

O presente estudo mensurou o valor econômico da produção agropecuária destinada para o autoconsumo e para a venda e também dos gastos com a compra de alimentos, para dimensionar a contribuição e o impacto deles no rendimento de famílias assentadas no baixo sul da Bahia.

Evidenciou-se que a produção para o autoconsumo é uma estratégia de reprodução social adotada por todas as famílias, que desenvolvem a produção diversificada de alimentos destinada para esse fim, apontando para um perfil camponês do grupo estudado. A produção para o autoconsumo constitui uma das bases dos estilos de agricultura, centrada no cultivo agroecológico de vegetais, com escassa presença de produção animal. Como foi evidenciado a produção para autoconsumo contribui de forma expressiva na composição da renda familiar.

O estudo também revela que a produção agropecuária com caráter comercial apresenta elevada dependência do cultivo de cacau, que é predominante na composição da renda das famílias. Os estilos de agricultura constituídos na produção comercial também são baseados na agroecologia e mostram-se bastante independentes do mercado de insumos, mas, por outro lado, apontam para uma inserção subordinada e individualizada das famílias nas cadeias globais de valor, dado que essa produção não é beneficiada no assentamento e é comercializada através de atravessadores.

Nesse sentido, em que pese os benefícios ambientais do sistema de cultivo agrossilvicultural do cacau, aponta-se a importância de dialogar com as famílias sobre a importância da diversificação das atividades produtivas de caráter comercial e também sobre a configuração de novas modalidades de organização da produção, de agroindustrialização e comercialização dos produtos agropecuários, com especial destaque para as formas associativas, na perspectiva de ampliação de sua renda e autonomia. Nessa perspectiva, compreende-se que a intensificação da produção dos alimentos com características de alternatividade (couve, cupuaçu, farinha de mandioca e banana) constitui-se como um viés muito interessante a ser considerado pelas famílias.

Consoante às observações realizadas, ainda que sob um viés econômico, algumas sinalizações podem ser apontadas para compor uma pauta sobre desenvolvimento rural a ser dialogada com as famílias. Como demonstrado, parte expressiva da renda familiar é comprometida com a compra de alimentos, o que permite cogitar-se a possibilidade de discutir eventuais alterações nas dietas das famílias, de forma articulada com ajustes nos sistemas produtivos. Obviamente isso precisaria ser devidamente localizado no contexto cultural das famílias e de suas aspirações. O que se pretende destacar é que, na imbricação dos estilos de agricultura e das práticas alimentares - destacadamente a compra de alimentos, o estudo sinaliza para a importância da potencialização da produção animal já existente no assentamento e a eventual incorporação de outros pequenos animais nos sistemas produtivos, bem como a ampliação e diversificação da produção vegetal para 0 autoconsumo, aliado à substituição do consumo de produtos ultraprocessados por alimentos produzidos pelas próprias famílias.

Esta pauta deveria estar presente no escopo das políticas públicas, que se apresentam de forma incipiente no assentamento, bem como ter sua pertinência analisada pelas famílias assentadas. Os resultados aqui apresentados permitem 
concluir que são ações de elevada importância para a qualificação das práticas alimentares e dos sistemas produtivos, tendo efeitos diretos e positivos na renda e na saúde do grupo analisado. Além disso, elas se alinham e apontam no sentido da potencialização de sistemas alimentares mais resilientes, sustentáveis e saudáveis.

Nessa perspectiva, o aprofundamento dos estudos remete a observação mais detalhada dos aspectos simbólicos associados a cultura alimentar, as práticas agrícolas e de comercialização desenvolvidas pelas famílias. Uma abordagem nessa perspectiva possibilitaria melhor compreensão da complexidade que envolve as práticas de produção e consumo entre os camponeses, dado o viés econômico que pautou o presente estudo. Isso possibilitaria avançar no entendimento das causas do frágil uso da estratégia da alternatividade, da cooperação e também das barreiras ao avanço da produção animal, para além dos limites identificados, destacadamente a disponibilidade de terra e a efêmera presença das políticas públicas.

\section{AGRADECIMENTOS}

Registramos nossos agradecimentos ao Instituto Educar (Pontão-RS), a Universidade Federal da Fronteira Sul (Erechim-RS) e ao Instituto Nacional de Colonização e Reforma Agrária (INCRA), pelo suporte ao trabalho de pesquisa que fundamenta o presente artigo.

\section{REFERÊNCIAS}

ALMEIDA, J. A modernização da agricultura. Porto Alegre: UFRGS, 2011.

BURSCH, D.; LAWRENCE, G. Towards a third food regime: behind the transformation. Agriculture and Human Values, Amsterdam, v. 26, n. 4, p. 267-279, 2009. Disponível em: https://link.springer.com/article/10.1007/s10460-009-9219-4. Acesso em: 15 jan. 2018.

BUSATO, M. A.; GALLINA, L. S; DREYER, D. C.; QUADROS, J. C. de; LAVRATTI, E.; TEO, C. R. P. A. Segurança Alimentar e Nutricional e as condições do ambiente em assentamento rural de Santa Catarina. Alim. Nutr., Araraquara, v. 22, n. 4, p. 555559, out./dez. 2011. Disponível em: https://www.unochapeco.edu.br/static/data/portal/downloads/2703.pdf. Acesso em: 20 jan. 2019.

CONTERATO, M. A. A mercantilização da agricultura familiar no Alto Uruguai/RS: um estudo de caso no município de Três Palmeiras. 2004. 208 f. Dissertação (Mestrado em Desenvolvimento Rural) - Programa de Pós-Graduação em Desenvolvimento Rural, Universidade Federal do Rio Grande do Sul, Porto Alegre, 2004.

CONTERATO, M. A. Dinâmicas regionais do desenvolvimento rural e estilos de agricultura: uma análise a partir do Rio Grande do Sul. 2008. 290 f. Tese (Doutorado em Desenvolvimento Rural) - Programa de Pós-Graduação em Desenvolvimento Rural, Universidade Federal do Rio Grande do Sul, Porto Alegre, 2008.

CONTERATO, M. A.; NIEDERLE, P. A.; RADOMSKY, G.; SCHNEIDER, S. Mercantilização e mercados: a construção da diversidade da agricultura na ruralidade contemporânea. In: SCHNEIDER, S.; GAZOLLA, M (Orgs.). Os atores do 
desenvolvimento rural: perspectivas teóricas e práticas. Porto Alegre: Editora da UFRGS, 2011.

DOMBEK, L. A. Autoconsumo e segurança alimentar em assentamentos rurais do Pontal do Paranapanema. 2006. 106 f. Dissertação (Mestrado em engenharia Agrícola) - Programa de Pós-Graduação em Engenharia Agrícola, UNICAMP, Campinas, 2006.

DUVAL, H. C. Da terra ao prato: um estudo das práticas de autoconsumo em um assentamento rural. 2009. 207 f. Dissertação (Mestrado em Agroecologia e Desenvolvimento Rural) - Programa de Pós-Graduação em Agroecologia e Desenvolvimento Rural, Universidade Federal de São Carlos, Araras, 2009.

DUVAL, H. C.; FERRANTE, V. L. S. B.; BERGAMASCO, S. M. P. P. Autoconsumo e as escalas de diversificação agrícola em um assentamento rural. Raízes, Campina Grande, v.32, n.2, p. 32-55, jul./dez. 2012. DOI: https://doi.org/10.37370/raizes.2012.v32.357. Disponível em: http://raizes.revistas.ufcg.edu.br/index.php/raizes/article/view/357. Acesso em: 19 ago. 2018.

FONTOURA, A. F. A produção para autoconsumo: características e importância para os sistemas de produção de pecuária familiar da Fronteira Oeste do RS. 2012. 150 f. Dissertação (Mestrado em Extensão Rural) - Programa de Pós-Graduação em Extensão Rural, Universidade Federal de Santa Maria, Santa Maria, 2012.

GARCIA JR., A. R.; HEREIDA, B. A. Campesinato, família e diversidade de explorações agrícolas no Brasil. In: GODOI, E. P.; MENEZES, M. A.; MARIN, R. A. (Orgs.). Diversidade do campesinato: expressões e categorias. São Paulo: Editora UNESP; Brasília: NEAD, 2009.

GAZOLLA, M. Agricultura familiar, segurança alimentar e políticas públicas: uma análise a partir da produção para autoconsumo no território do Alto Uruguai/RS. 2004. 305 f. Dissertação (Mestrado em Desenvolvimento Rural) - Programa de PósGraduação em Desenvolvimento Rural, Universidade Federal do Rio Grande do Sul, Porto Alegre, 2004.

GAZOLLA, M.; SCHNEIDER, S. Cadeias curtas e redes agroalimentares alternativas. In: GAZOLLA, M.; SCHNEIDER, S (Orgs.). Cadeias curtas e redes agroalimentares alternativas: negócios e mercados da agricultura familiar. Porto Alegre: Editora da UFRGS, 2017.

GRISA, C. A produção "pro gasto": um estudo comparativo do autoconsumo no Rio Grande do Sul. 2007. 200 f. Dissertação (Mestrado em Desenvolvimento Rural) Programa de Pós-Graduação em Desenvolvimento Rural, Universidade Federal do Rio Grande do Sul, Porto Alegre, 2007.

GRISA, C.; SCHNEIDER, S. Plantar pro gasto: a importância do auto consumo entre famílias de agricultores do Rio Grande do Sul. Rev. Econ. Sociol. Rural, Piracicaba, v. $46, \quad$ n. 2 , p. $481-515,2008$ a. DOI: http://dx.doi.org/10.1590/S0103$20032008000200008 . \quad$ Disponível em: https://www.scielo.br/scielo.php?script=sci_arttext\&pid=S0103-20032008000200008. Acesso em: 19 ago. 2018. 
GRISA, C.; SCHNEIDER, S. Fatores determinantes da produção para autoconsumo na agricultura familiar: um estudo comparativo no Rio Grande do Sul. Teoria \& Pesquisa, São Carlos, n. 17, p. 47-74, 2008b. Disponível em: http://www.teoriaepesquisa.ufscar.br/index.php/tp/article/viewFile/148/112. Acesso em: 17 ago. 2018.

INSTITUTO BRASILEIRO DE GEOGRAFIA E ESTATÍSTICA- IBGE. Censo Agropecuário. 2017. Disponível em: http://www.ibge.gov.br/. Acesso em: 10 jan. 2019.

INSTITUTO BRASILEIRO DE GEOGRAFIA E ESTATÍSTICA- IBGE. Pesquisa Nacional por Amostra de Domicílios Contínua - PNADC. 2019. Disponível em: https://www.ibge.gov.br/busca.html?searchword=PNADC. Acesso em: 12 jan. 2019.

JAEHN, E. A importância do autoconsumo na renda das famílias assentadas no Rio Grande do Sul. 2019. 129 f. Dissertação (Mestrado em Extensão Rural) Programa de Pós-Graduação em Extensão Rural, Universidade Federal de Santa Maria, Santa Maria, 2019.

LEITE, S. Orçamentos familiares e estratégias socioeconômicas em assentamentos rurais. Estudos Sociedade e Agricultura, Rio de Janeiro, n. 21, p. 118-151, 2003. Disponível em: https://revistaesa.com/ojs/index.php/esa/article/view/241. Acesso em: 28 de mar. 2021.

LIMA, A. J. P. BASSO, N. NEUMANN, P. S. SANTOS, A. C. MÜLleR, A. G. Administração da Unidade de Produção Familiar: modalidades de trabalho com agricultores. ljuí: Editora UNIJUÍ, 1995.

LOBÃO, D. É. Manual do cacau cabruca: sistema agrossilvicultural tropical. CEPLAC: Ilhéus, 2013.

LONG, N. Sociología del desarrollo: una perspectiva centrada en el actor. México: Ciesas, 2007.

LONG, N.; PLOEG, J. D. V. Heterogeneity, actor and structure: towards a reconstitution of the concept of structure. In: BOOTH, D. Rethinking social development: theory, research and practice. Harlow: Longman, 1994.

MAIA, A. G. O esvaziamento demográfico rural. In: BUAINAIN, A. M. et al (Orgs.). 0 mundo rural no Brasil do século 21: a formação de um novo padrão agrário e agrícola. Brasília: EMBRAPA, 2014.

MATTEI, L. A política agrária e rural do governo Temer. In: MALUF, R. S.; FLEXOR, G. Questões agrária, agrícolas e rurais: conjunturas e políticas públicas. Rio de Janeiro: e-papers, 2017.

MENASCHE, R.; MARQUES, F. C.; ZANETTI, C. Autoconsumo e segurança alimentar: a agricultura familiar a partir dos saberes e práticas da alimentação. Revista de Nutrição, Campinas, v. 21, p. 145-158, jul./ago., 2008. Disponível em: https://www.scielo.br/pdf/rn/v21s0/13.pdf. Acesso em: 18 ago. 2018. 
NESTLE, M. Food Politics: how the food industry influences nutrition and health. Berkeley: University of California Press, 2013.

OLIVEIRA, M. L. S.; KALSING, V. S. S.; OLIVEIRA, R. A.; OLIVEIRA, B. A. M.; PEREIRA, V. S. Mulheres, relações de gênero e divisão sexual do trabalho em Minas Gerais: negras, assentadas de reforma agrária e da economia solidária em Lavras, Guapé e Prados. Retratos de Assentamentos, Araraquara, v. 18, n.1, p. 17-42, 2015. DOI:https://doi.org/10.25059/2527-2594/retratosdeassentamentos/2015.v18i1.179.

Disponível

em: https://retratosdeassentamentos.com/index.php/retratos/article/view/179. Acesso em: 12 ago. 2018.

PIASENTIN, F. B. O sistema cabruca no sudeste da Bahia: perspectivas de sustentabilidade. 2011. 200 f. Tese (Desenvolvimento sustentável) - Centro de Desenvolvimento sustentável, Universidade de Brasília, Brasília, 2011.

PLOEG, J. D. V. Styles of farming: an introductory note on concepts and methodology. In: PLOEG, J. D. van der; LONG, A. Born from within. Assen: Van Gorcum, 1994.

PLOEG, J. D. V. Camponeses e impérios alimentares: lutas por autonomia e sustentabilidade na era da globalização. Porto Alegre: Editora da UFRGS, 2008.

PLOEG, J. D. V. O modo de produção camponês revisitado. In: SCHNEIDER, S. A diversidade da agricultura familiar. 2. ed. Porto Alegre: Editora da UFRGS, 2009.

PLOEG, J. D. V. Camponeses e a arte da agricultura. São Paulo: Editora UNESP; Porto Alegre: Editora UFRGS, 2016.

POZZEBOM, L. et al. Repercussões territoriais das feiras de produtos coloniais e agroecológicos de Chapecó/SC: considerações sobre a SAN e o autoconsumo dos agricultores familiares. In: SEMINÁRIO INTERNACIONAL SOBRE DESENVOLVIMENTO REGIONAL, 7., 2015, Santa Cruz do Sul, RS. Anais... Santa Cruz do Sul: UNISC, 2015. p. 1-22.

RITZER, G. F. The McDonaldization of society. Journal of American Culture, Bowling, v.6, n.1, p. 100-107, 1983. Doi: https://doi.org/10.1111/j.1542734X.1983.0601_100.x .Disponível em: https://onlinelibrary.wiley.com/doi/10.1111/j.1542-734X.1983.0601_100.x. Acesso em: 19 ago. 2018.

SALAMI, A. Hábitos alimentares de agricultores familiares assentados de Abelardo Luz - SC. 2009. 96 f. Dissertação (Mestrado em Agroecossistemas) Programa de Pós-Graduação em Agroecossistemas, Universidade Federal de Santa Catarina, Florianópolis, 2009.

SCHNEIDER, S. A pluriatividade na agricultura familiar. 2. ed. Porto Alegre: Editora da UFRGS, 2010.

SCHNEIDER, S.; ESCHER, F. El concepto de agricultura familiar en América Latina. In: CRAVIOTTI, C. Agricultura familiar en Latinoamérica: continuidad, transformaciones y controversias. Buenos Aires: CICCUS, 2014. 
SILVEIRA, D. T.; CÓRDOVA, F. P. A pesquisa científica. In: GERHARDT, T. E.; SILVEIRA, D. T (Orgs.). Métodos de Pesquisa. Porto Alegre: Editora da UFRGS, 2009.

THIES, V. F. Desagrarização e concentração produtiva: análise longitudinal das trajetórias da agricultura familiar nas Missões do RS. 2020. 195 p. Tese (Doutorado em Desenvolvimento Rural) - Programa de Pós-Graduação em Desenvolvimento Rural, Universidade Federal do Rio Grande do Sul, Porto Alegre, 2020.

TONEZER, C.; PINHEIRO, E.; PAGNUSSAT, L. Quanto vale a produção para o autoconsumo no meio rural? Um estudo de caso no município de Coronel Freitas no Oeste Catarinense. Extensão Rural, Santa Maria, v.26, n.4, p. 90-107, out./dez. 2019. DOI: https://doi.org/10.5902/2318179639470. Disponível em: https://periodicos.ufsm.br/extensaorural/article/view/39470. Acesso em: 17 jan. 2020.

WANDERLEY, M. de N. B. Agricultura familiar e campesinato: rupturas e continuidade. Estudos Sociedade e Agricultura, Rio de Janeiro, n. 21, p. 42-61, out. 2003. Disponível em: https://revistaesa.com/ojs/index.php/esa/article/view/238. Acesso em: 17 ago. 2018.

WEDIG, J. C.; MENASCHE, R. Comida e classificações: homens e mulheres em famílias camponesas. Caderno Espaço Feminino, Uberlândia, v. 20, n. 02, ago./dez., p. 57-74, 2008. Disponível em: http://www.seer.ufu.br/index.php/neguem/article/view/2136. Acesso em: 19 ago. 2018.

YIN, R. K. Estudo de caso: planejamento e métodos. 2. ed. Porto Alegre: Bookman, 2001. 